\title{
Socially transmitted food preferences can be used to study long-term memory in rats
}

\author{
BENNETT G. GALEF, JR., and ELAINE E. WHISKIN \\ McMaster University, Hamilton, Ontario, Canada
}

\begin{abstract}
Immediately after a recently fed rodent demonstrator interacts with a conspecific observer, the observer shows a substantially enhanced preference for whatever food its demonstrator ate. Here we show that (1) influence of a single, 30-min interaction with a demonstrator on an observer's food preference lasts for at least 1 month, and (2) observers interacting on 2 successive days with a demonstrator fed a different diet on each day show significantly enhanced preferences for both diets a month later. Such enduring effects of single, brief interactions between a demonstrator rat and its observer provide an efficient means for studying physiological and behavioral substrates of long-term memory in rodents. Together with the results of previous studies of social influences on food choices of rats, the present results also suggest that rats may use information acquired from conspecifics to identify both toxic and safe foods for many weeks after they have acquired this information.
\end{abstract}

After a Norway rat (an observer) interacts briefly with a conspecific that has eaten a distinctively flavored food (a demonstrator), the observer shows substantial enhancement of its preference for whatever food its demonstrator ate (Galef \& Wigmore, 1983). This one-trial procedure for inducing a learned flavor preference, described in detail in Galef (2002), provides a simple, noninvasive, costeffective way to produce robust changes in appetitive behavior not only in Norway rats (Rattus norvegicus), but also in house mice (Mus domesticus; Valsecchi \& Galef, 1989), Mongolian gerbils (Meriones unguiculatus; Galef et al., 1998), pine voles (Microtus pinetorum; Solomon, Yaeger, \& Beeler, 2002), spiny mice (Acomys cahirinus; McFadyen-Ketchum \& Porter, 1989), and Belding's ground squirrel (Spermophilus beldingii; Peacock \& Jenkins, 1988).

Results of previous studies have shown that Norway rats can use information acquired from conspecifics concerning foods that they have eaten, both directly, to select nutritious foods to eat (Beck \& Galef, 1989; Galef \& Wigmore, 1983), and indirectly, to avoid ingesting toxins (Galef, 1986, 1987). For example, naive rats, faced with a choice of four foods only one of which contained sufficient protein for normal growth, focused their feeding on the nutritionally adequate diet significantly faster when housed with conspecifics trained to eat the adequate diet than if housed alone (Beck \& Galef, 1989). Naive rats, after having eaten two unfamiliar foods before becoming ill, subsequently avoided whichever of those foods was not eaten by a conspecific with which

This research was supported by grants from the Natural Sciences and Engineering Research Council of Canada. Correspondence should be addressed to B. G. Galef, Jr., Department of Psychology, McMaster University, Hamilton, ON, L8S 4K1, Canada (e-mail: galef@ mcmaster.ca). they had interacted before eating both foods and falling ill (Galef, 1986, 1987).

Changes in rodents' acceptance of unfamiliar foods have potential for studies of the neuroanatomical, neurochemical, and genetic substrates of learning and memory (see, e.g., Burnsey \& Eichenbaum, 1995; Kogan et al., 1996; Winocur, 1990). However, at least in part because little evidence is available as to the duration of effects of social influences on food choices of rodents, this potential has not been fully realized (Howard Eichenbaum, personal communication).

Providing evidence that effects of demonstrators on their observers' diet preferences are of long duration is time consuming and, therefore, expensive, so it should come as no surprise that few relevant studies have been conducted. Galef (1989) has shown that repeated interactions with demonstrators fed a diet will sustain preference for that diet in observers continuously offered a choice between the diet that their respective demonstrators have eaten and an alternative. However, although such methods show that social influences on food choice can be sustained over substantial periods, they tell us little about long-term memory for information acquired by observers from their demonstrators.

Here we show, first, that effects of a single interaction with a demonstrator on an observer's food preferences can last for a month or more, and second, that an individual rat can acquire two food preferences from a demonstrator at separate times and still show effects of both instances of social learning 1 month later. Both findings provide evidence that social learning of food preference is a suitable procedure for studies of long-term memory in rodents. The latter demonstration suggests further that experimental manipulations could be carried out in the same subject both before and after induction of a food preference, permitting a subject to serve as its own con- 
trol in studies of effects of independent variables on long-term memory.

The procedures for demonstrating long-term memory in rats explored here have several advantages: (1) Learning occurs in a single, brief trial, (2) learning is robust, (3) little effort or skill on the part of the experimenter is needed to train subjects, (4) large numbers of trained subjects can be produced at relatively little cost, (5) learning is appetitively rather than aversively motivated, and (6) subjects need not be deprived or subjected to stress of any kind for training.

\section{EXPERIMENT 1}

Our first experiment was simply a replication of the basic finding of Galef and Wigmore (1983) of a profound effect of flavors ingested by demonstrator rats on food preferences of their observers. However, in the present study, in addition to testing food choices of observers immediately after they interacted with their respective demonstrators, we also examined observers' food preferences both 1 and 4 weeks after interaction between demonstrator and observer. Although others have demonstrated effects of social learning about foods either 1 (e.g., Burnsey \& Eichenbaum, 1995; Kogan et al., 1996; Solomon et al., 2002) or 8 days (Winocur, 1990) following social interaction, the present experiment is the first to examine such effects several weeks after social induction of a food preference.

\section{Method}

Subjects. Forty-eight female Long-Evans rats obtained from Charles River Canada (St. Constant, Quebec) when 42 days of age served as observers. An additional forty-eight 49- to 56-day-old female Long-Evans rats that had served as observers in other experiments served as demonstrators.

Apparatus. Throughout the experiment, each subject resided in an individual, wire-mesh, hanging cage $(21.5 \times 24 \times 27.5 \mathrm{~cm})$ and ate from semicircular, stainless-steel cups ( $8 \mathrm{~cm}$ diam, $4 \mathrm{~cm}$ deep). To prevent spillage, we filled food cups to a depth of $2 \mathrm{~cm}$ or less, and to monitor spillage, we placed a paper towel under each subject's cage.

Diets. We composed two distinctively flavored diets by adding either $2.0 \mathrm{~g}$ of Hershey's Pure Cocoa (Diet Coc) or $1.0 \mathrm{~g}$ of bulk ground cinnamon (Diet Cin) to $100 \mathrm{~g}$ of powdered Purina Rodent Laboratory Chow 2001 (Diet Pur).

Procedure (demonstrators). Twenty-four hours after we introduced the demonstrator rats into their respective cages, we placed them on a 23-h schedule of food deprivation. While on schedule, the demonstrators had access to Diet Pur for $1 \mathrm{~h} /$ day for 2 consecutive days. Twenty-three hours after each demonstrator's second scheduled feeding on Diet Pur, we introduced a weighed food cup containing Diet Cin into the home cages of 24 demonstrators and a weighed food cup containing Diet Coc into the home cages of the remaining 24 demonstrators. One hour later, we removed the food cup from each demonstrator's cage and then introduced the demonstrator into the home cage of an observer rat, where demonstratorobserver pairs then interacted freely for $30 \mathrm{~min}$. At the end of the 30-min period of interaction between demonstrator and observer, we returned each demonstrator to its home cage. This ended the participation of demonstrators in the experiment.

Procedure (observers). During the first 2 days of the experiment (while we habituated the demonstrators to their restricted schedule of feeding), we provided each observer with ad-lib access to pellets of Diet Pur. We removed these pellets just before we introduced each demonstrator into its observer's cage.

To determine effects on the observers' food choices of interacting with demonstrators, we placed two weighed food cups, one containing Diet Cin and the other Diet Coc, into the home cage of each observer for $24 \mathrm{~h}$ immediately (0-delay group), 7 days (7-day-delay group) or 30 days (30-day-delay group) after we removed the demonstrators from their respective observers' home cages. Observers assigned to 7-day-delay and 30-day-delay conditions had ad-lib access to pellets of Diet Pur during the days between removal of the demonstrators from the observers' cages and placement of food cups containing Diets Cin and Coc in observers' cages.

\section{Results and Discussion}

Data from 1 subject assigned to each of the three condition were lost because (1) 1 demonstrator failed to eat, (2) 1 observer overturned its food cups during the choice test, and (3) an error was made weighing food cups of 1 observer, leaving 15 subjects in each group.

The demonstrators ate an average $( \pm S E M)$ of $6.6 \pm$ $0.2 \mathrm{~g}$ during the 1 - $\mathrm{h}$ feeding period that immediately preceded interaction with observers, and the observers ate an average of $25.8 \pm 1.2 \mathrm{~g}$ during the 24 -h choice test.

The main results of experiment are presented in Figure 1. Figure 1 shows the amount of Diet Cin eaten, as a percentage of total intake during the 24-h choice test, by observers assigned to 0-, 7-day-, and 30-day-delay conditions, whose respective demonstrators had eaten either Diet Cin or Diet Coc. As can be seen in Figure 1, the enhanced preference for demonstrators' diets seen in observers assigned to the 0 -delay condition [Student's $t$ test, $t(13)=2.69, p<.02]$ was still present both 7 days $[t(13)=$ $3.90, p<.002]$ and 30 days $[t(13)=2.33, p<.04]$ after demonstrators and observers had interacted. Indeed a one-way analysis of variance (ANOVA) examining the percentage of each observer's 24 -h intake during testing that was the diet that its demonstrator had eaten (i.e., the percentage of total intake of observers that had inter-

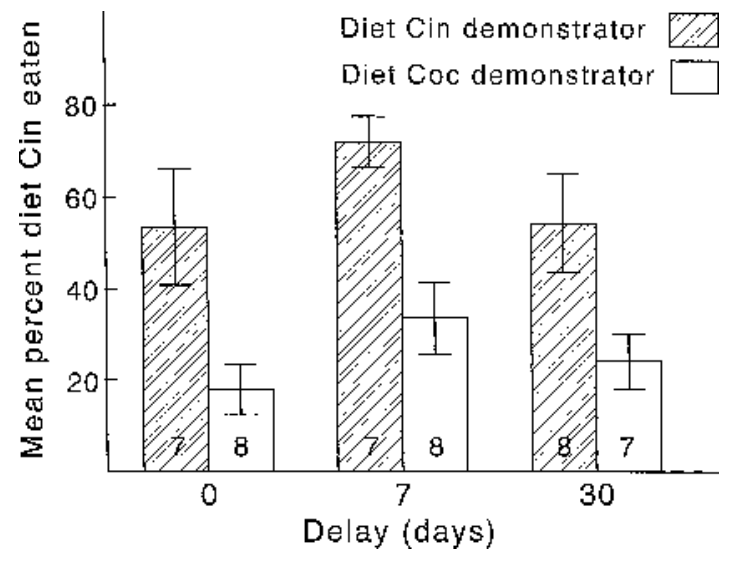

Figure 1. Mean amount of Diet Cin eaten, as a percentage of total 24-h intake of Diets Cin and Coc, by observers assigned to 0-, 7-, and 30-day-delay conditions whose demonstrators had eaten either Diet Cin or Diet Coc. Numbers within histograms = $n /$ group. Error bars $= \pm 1 S E M$. 
acted with demonstrators fed Diet Cin that was Diet Cin and the percentage of total intake of observers that had interacted with demonstrators fed Diet Coc that was Diet Coc) revealed no effect of delay on the magnitude of demonstrators' influence on their observers' diet choices $[F(2,42)=0.17$, n.s. $]$.

Clearly, effects of demonstrator rats on the food choices of their observers are of sufficient duration to allow the use of socially learned food preferences in studies of mechanisms of long-term memory in Norway rats.

\section{EXPERIMENT 2}

In two previous experiments, we have examined effects on observers' food choices following interaction with either a demonstrator fed a diet containing several different flavorants (Galef \& Whiskin, 1992) or a series of demonstrators each of which had eaten a different-flavored diet (Galef, 1983). In the former study, we compared food choices of observers that had, for example, interacted with demonstrators fed a diet flavored with cinnamon, anise, and marjoram, with those of observers that had interacted with demonstrators fed a diet flavored with cocoa, anise, and marjoram. We found that, immediately following interaction with a demonstrator, observers that had interacted with a demonstrator that had cinnamon in its multiflavored diet ate more cinnamon than did observers that had interacted with a demonstrator that had cocoa in its multiflavored diet (Galef \& Whiskin, 1992). In the latter study, we provided evidence that observers that had interacted with a set of four demonstrators each fed a different diet showed an enhanced preference for each of those diets (Galef, 1983). We did not determine in either study the effects of exposure to demonstrators eating more than one diet on subsequent food preferences of a single observer for each diet that its demonstrator had eaten. Neither did we examine the duration of effects of demonstrators on their observers' diet choices.

Here, we examined long-term effects of interaction with a demonstrator rat fed two different diets on successive days on food choices of a single observer that had interacted with the demonstrator immediately after it had eaten each diet. The present procedure has the advantage that, if successful, it should allow the use of a subject as its own control in studies of effects on a single observer's memory of manipulations occurring before and after acquisition of information from a demonstrator.

\footnotetext{
Method

Subjects. Sixty female Long-Evans rats obtained from Charles River Canada (St. Constant, Quebec) when 42 days of age served as observers. A further 60 rats, 49 to 56 days old, that had served as observers in previous experiments served as demonstrators.

Apparatus. We used the same apparatus as in Experiment 1.

Diets. In addition to the three diets used in Experiment 1 (i.e., Diets Cin, Coc, and Pur), we used two new diets, Diet Ani and Diet Mar, composed, respectively, by adding either $1 \mathrm{~g}$ of ground anise or $2.4 \mathrm{~g}$ of ground marjoram to $100 \mathrm{~g}$ of Diet Pur.
}

Procedure. The procedure was similar to that of Experiment 1, with three exceptions. First, in the present experiment, each observer interacted with the same demonstrator for $1 \mathrm{~h}$ twice, once immediately after its demonstrator had eaten either Diet Cin or Diet Coc and again the next day immediately after the same demonstrator had eaten either Diet Mar or Diet Ani. We counterbalanced across observers the order in which we gave Diets Ani or Mar and Coc or Cin to demonstrators. Second, we tested each observer's food preferences on 2 days, first by giving it a choice between Diets Cin and Coc for $24 \mathrm{~h}$, and immediately thereafter, giving it $24 \mathrm{~h}$ to choose between diets Mar and Ani. Third, we assigned subjects to only 0 -delay and 30 -day-delay conditions. We tested 36 subjects in the 0 -delay condition, and to keep down the cost of maintaining animals in the laboratory for 30 days, we tested only 24 subjects in the 30-day-delay condition.

\section{Results and Discussion}

We lost some data from each of 3 subjects that spilled food during one or both of their two 24-h choice tests.

When eating either Diet Cin or Diet Coc, demonstrators ate on average $( \pm S E M) 6.6 \pm 0.2 \mathrm{~g}$, and on the next day, when eating Diets Ani or Mar, they ate an average of $7.8 \pm 0.2 \mathrm{~g}$. The significant increase in intake of demonstrators between the third and fourth days of scheduled feeding [Student's $t$ test, $t(45)=4.24, p<.0001$ ] would be expected as demonstrators became better adapted to their feeding schedule.

When choosing between Diets Cin and Coc, observers assigned to the 0 -delay condition ate an average $21.2 \pm$ $0.4 \mathrm{~g}$ and when choosing between Diets Ani and Mar an average of $21.2 \pm 0.5 \mathrm{~g}$. Similarly, observers assigned to the 30-day-delay condition ate an average of $26.0 \pm 0.7 \mathrm{~g}$ when choosing between Diets Cin and Coc, and an average of $23.2 \pm 0.5 \mathrm{~g}$ when choosing between Diets Mar and Ani. This increase in intake would be expected as observers increased in age and body weight.

Figure 2 shows the amounts of Diet Cin and Diet Ani eaten, as a percentage of total amount ingested during $24 \mathrm{~h}$, by observers assigned to the 0 -delay condition offered a choice, first between Diets Cin and Coc, then between Diets Ani and Mar. As can be seen in the left panel of Figure 2: (1) When offered a choice between Diets Cin and Coc, those observers one of whose demonstrators had eaten Cin ate more Diet Cin than did those observers one of whose demonstrators had eaten Diet Coc [ $2 \times 2$ ANOVA, $F(1,65)=17.15, p<.0001]$, and, as can be seen in the right panel of Figure 2, (2) when offered a choice between Diets Ani and Mar, those observers one of whose demonstrators had eaten Diet Ani ate more Diet Ani than did those observers one of whose demonstrators had eaten Diet Mar $[F(1,67)=20.95, p<.03]$. On the other hand, exposure to demonstrators eating either Diet Cin or Diet Coc had no effect on observers' preferences in choosing between Diets Ani and Mar $[F(1,65)=3.2$, n.s. $]$, and exposure to demonstrators eating either Diet Ani or Diet Mar had no effect on observers' preferences in choosing between Diets Cin and $\operatorname{Coc}[F(1,67)=0.31$, n.s.]. There was also no significant interaction between main effects on either diet choice [both $F \mathrm{~s}(1,43)<2.82$, n.s.]. 

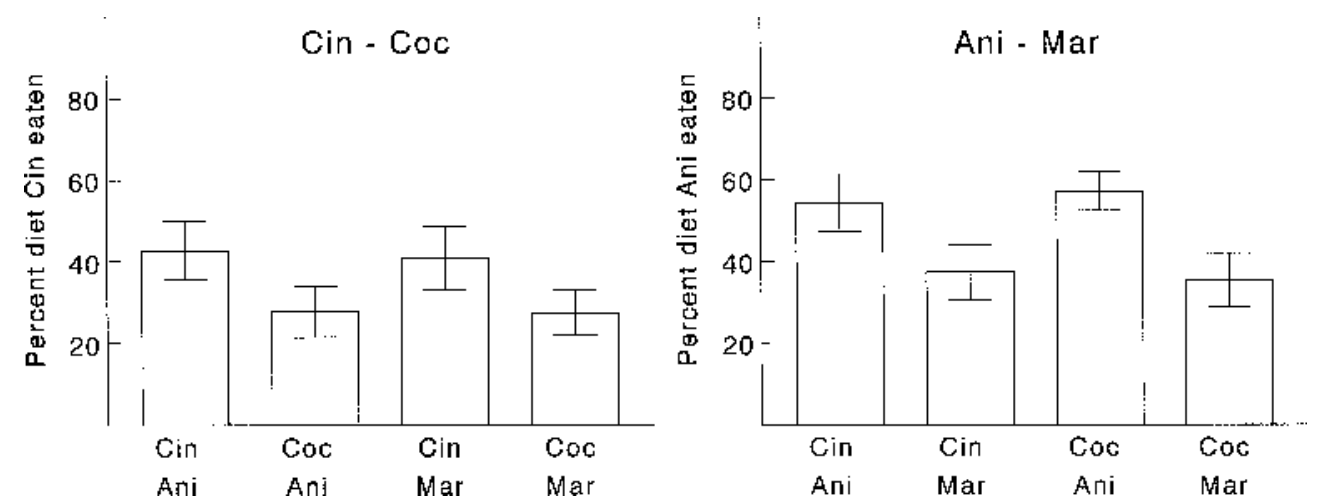

Figure 2. The two panels show the mean amount of Diet Cin or Diet Ani eaten by observers during the $24 \mathrm{~h}$ immediately after interacting with a demonstrator fed two different diets. The choice of diets offered to each group of observers is indicated by the floating titles in each panel. Foods eaten by demonstrators are shown below each histogram. Error bars $= \pm 1 S E M$.

Figure 3 shows the amounts of Diets Cin and Ani, as a percentage of total amount eaten during $24 \mathrm{~h}$, by observers assigned to the 30-day-delay condition offered a choice, first between Diets Cin and Coc, then between Diets Ani and Mar. As can be seen in the left panel of Figure 3: (1) When offered a choice between Diets Cin and Coc, observers whose demonstrators had eaten Diet Cin ate more of that diet than did observers whose demonstrators had eaten Diet Coc $[2 \times 2$ ANOVA, $F(1,43)=4.49, p<.04]$, and (2) as can be seen in the right panel of Figure 3, when offered a choice between Diets Ani and Mar, those observers whose demonstrators had eaten Ani ate more of that diet than did those observers whose demonstrators had eaten Diet Mar $[F(1,43)=5.13, p<.03]$. On the other hand, exposure to demonstrators eating either Diet Cin or Diet Coc had no effect on observers' preferences in choosing between Diets Ani and $\operatorname{Mar}[F(1,43)=0.55$, n.s.], and exposure to demonstrators eating either Diet Ani or Diet Mar had no effect on observers' preferences in choosing between Diets Cin and Coc $[F(1,43)=0.55$, n.s. $]$. There was also no significant interaction between main effects on either diet choice [both $F_{\mathrm{S}}(1,43)<1.37$, n.s.].

When we calculated the mean percentage intake by observers assigned to 0-delay and 30-day-delay conditions that was of the diet that their respective demonstrators had eaten, we found no effect of delay on degree of correspondence between demonstrators' diet and observers' diet choices [Student's $t$ tests: for observers whose demonstrators had eaten either Diet Cin or Diet Coc when choosing between Diets Cin and Coc, $t(116)=1.33$, n.s.; for observers choosing between Diets Mar and Ani whose demonstrators had eaten either Diet Mar or Diet Ani, $t(114)=0.80$, n.s.].

Socially induced preferences for two different foods lasting at least 1 month can be induced in the same observer rat. Consequently, an observer rat can be used as its own control in studies of the effects of an independent variable on memories for flavors.
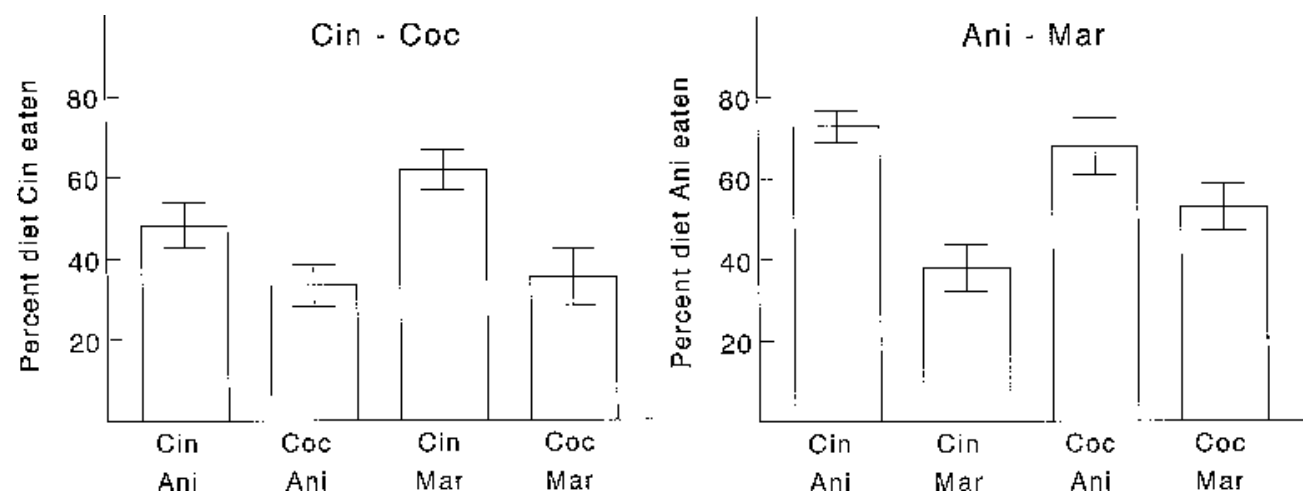

Figure 3. The two panels show the mean amount of Diet Cin or Diet Ani eaten by observers during $24 \mathrm{~h}$ 30 days after interacting with a demonstrator fed two different diets. The choice of diets offered to each group of observers is indicated by the floating titles in each panel. Foods eaten by demonstrators are shown below each histogram. Error bars $= \pm 1$ SEM. 


\section{GENERAL DISCUSSION}

Taken together, the present results provide strong evidence of month-long effects of social influences on food preferences of Norway rats. Thirty days after observer rats had interacted on a single occasion with a conspecific demonstrator that had eaten a food unfamiliar to the observer, the observer still exhibited an enhanced preference for that food. Effects on diet choice of a single interaction of observers with demonstrators are not only robust (Galef, Kennett, \& Wigmore, 1984), they are also long lasting. Consequently, social learning of food preferences by Norway rats, and presumably by other rodents as well, provides a potentially useful paradigm for studies of long-term memory in rodents.

The finding that socially acquired information concerning foods continues to affect food choices of observer rats weeks after they have interacted with a demonstrator also has implications for our understanding of the role of social learning in the food choices of rats living in natural circumstances. The present evidence of retention in long-term memory of socially acquired information about more than one food suggests that, over time, individual rats can build a "library" of memories concerning foods others have eaten, and that they can use this collection of information when they select items to ingest (Galef \& Whiskin, 1992). To use information acquired from a demonstrator rat about food, an observer rat need not encounter that food soon after interacting with the demonstrator. Information acquired from a demonstrator can be used weeks after acquisition in responding to a potential food, whenever it is encountered.

Wild Norway rats exhibit extreme reluctance to ingest unfamiliar foods (Barnett, 1958; Galef, 1970). They are thus protected against ingestion of toxins (Rzoska, 1953). However, such dietary conservatism carries a potential lost-opportunity cost. Unfamiliar, safe, and nutritious foods, as well as unfamiliar toxins, are avoided. By storing and subsequently using information acquired from others concerning foods they have eaten, wild rats should be able to incorporate unfamiliar, desirable foods into their feeding repertoires while maintaining their avoidance of dangerous substances.

\section{REFERENCES}

BARnetT, S. A. (1958). Experiments on "neophobia" in wild and laboratory rats. British Journal of Psychology, 49, 195-201.

BECK, M., \& GALEF, B. G., JR. (1989). Social influences on the selection of a protein-sufficient diet by Norway rats. Journal of Comparative Psychology, 103, 132-139.
Burnsey, M., \& Eichenbaum, H. (1995). Selective damage to the hippocampal region blocks long-term retention of a natural and nonspatial stimulus-stimulus association. Hippocampus, 5, 546-556.

GALEF, B. G., JR. (1970). Aggression and timidity: Responses to novelty in feral Norway rats. Journal of Comparative \& Physiological Psychology, 71, 370-381.

GALEF, B. G., JR. (1983). Utilization by Norway rats (R. norvegicus) of multiple messages concerning distant foods. Journal of Comparative Psychology, 97, 364-371.

GALEF, B. G., JR. (1986). Social identification of toxic diets by Norway rats (R. norvegicus). Journal of Comparative Psychology, 100, 331334.

GALEF, B. G., JR. (1987). Social influences on the identification of toxic foods by Norway rats. Animal Learning \& Behavior, 15, 327-332.

GALEF, B. G., JR. (1989). Enduring social enhancement of rats' preferences for the palatable and the piquant. Appetite, 13, 81-92.

GALEF, B. G., JR. (2002). Social learning of food preferences in rodents: Rapid appetitive learning. In J. N. Crawley, C. R. Gerfen, M. A. Rogawski, D. R. Sibley, P. Skolnick, \& S. Wray (Eds.), Current protocols in neuroscience (pp. 8.5 D1 to 8.5 D8). New York: Wiley.

Galef, B. G., JR., KennetT, D. J., \& Wigmore, S. W. (1984). Transfer of information concerning distant food in rats: A robust phenomenon. Animal Learning \& Behavior, 12, 292-296.

Galef, B. G., Jr., Rudolf, B., Whiskin, E. E., Cholersi, E., MaiNARDI, M., \& VALSECCHI, P. (1998). Familiarity and relatedness: Effects on social learning about foods by Norway rats and Mongolian gerbils. Animal Learning \& Behavior, 26, 448-454.

GALEF, B. G., JR., \& WHISKIN, E. E. (1992). Social transmission of information about multiflavored foods. Animal Learning \& Behavior, 20, 56-62.

GaLeF, B. G., JR., \& Wigmore, S. W. (1983). Transfer of information concerning distant foods: A laboratory investigation of the "information centre" hypothesis. Animal Behaviour, 31, 748-758.

Kogan, J. H., Frankland, P. W., Blendy, J. A., Coblentz, J., Marowitz, Z., Schutz, G., \& Silva, A. J. (1996). Spaced training induces normal long-term memory in CREB mutant mice. Current Biology, 7, 1-11.

McFadyen-Ketchum, S. A., \& Porter, R. H. (1989). Transmission of food preferences in spiny mice (Acomys cahirinus) via nose-mouth interaction between mothers and weanlings. Behavioral Ecology \& Sociobiology, 24, 59-62.

Peacock, M. M., \& Jenkins, S. H. (1988). Development of food preferences: Social learning in Belding's ground squirrel (Spermophilus beldingii). Behavioral Ecology \& Sociobiology, 22, 393-399.

Rzoska, J. (1953). Bait shyness: A study in rat behavior. British Journal of Animal Behaviour, 1, 128-135.

Solomon, N. G., Yaeger, C. S., \& Beeler, L. A. (2002). Social transmission and memory of food preferences in pine voles (Microtus pinetorum). Journal of Comparative Psychology, 116, 35-38.

VAlsecCHI, P., \& GALEF, B. G., JR. (1989). Social influences on the food preferences of house mice (Mus musculus). International Journal of Comparative Psychology, 2, 245-256.

WINOCUR, G. (1990). Anterograde and retrograde amnesia in rats with dorsal hippocampal or dorsomedial thalamic lesions. Behavioural Brain Research, 38, 145-154.

(Manuscript received July 2, 2002; revision accepted for publication October 14, 2002.) 